\title{
Issues in Human GenEthics
}

Jorge M. Saraiva, $\mathrm{MD}, \mathrm{PhD}^{1}$, Elizabeth Anionwu, $\mathrm{Ph} \mathrm{D}^{2}$, Maria Belo, $P h D^{3}$, Trefor Jenkins, $M D^{4}$, Ulf Kristoffersson, $M D, P h D^{5}$, Isabel Marques, $P h D^{6}$, Heloisa G. Santos, $M D$, PhD ${ }^{7}$, Jorge Sequeiros, $M D, P h D^{8}$, Sheila A. Simpsom, $M D^{9}$, Dorothy Wertz, $P h D^{10}$, and Carolino Monteiro, $P h D^{11}$

The conference "Issues in Human GenEthics," which took place in Lisbon, Portugal, on June 16-17, 2000, was organized by the Portuguese Society of Human Genetics and The British Council. The main topics of discussion were genetic testing and human rights, education and communication in human genetics, and national bioethics committees and the challenge of human genome research. The presentations of the invited speakers, the discussion, and the documents presented by the reporters of each session were used to develop this consensus paper.

The pace and scope of change in science and biotechnology are unprecedented. Economic prosperity is nowadays unlikely without the effective exploitation of innovation. Education, research, and development are critical for a society to succeed in the future global economy, which will be knowledge-based with biosciences as a leading field.

As the pace of biotechnological innovation accelerates, ethical decisions about its acceptability will become more urgent. Although biotechnology in itself has no ethics, humans do.

Bioethics should seek to evaluate the ethical dimensions of biomedical research with the intention of making improvements rather than setting restrictions. If "What can I do?" is a scientific question, "What should I do?" is an ethical question. Bioethics should guide biotechnological development to help realize the potential of every human being, as well as to help the society in which they live. If the interests of the individual and society are different, we should comply with the Council of Europe's Convention of Human Rights and Biomedicine, which has established that the interests and well-being of each person should prevail over those of society or science.

Bioethics started as an interdisciplinary discussion from its very beginning, but society in the broadest sense needs to be involved. There should be ready public access to the subjects

\footnotetext{
From the ${ }^{1}$ Servico de Genetica Medica, Centro Hospitalar de Coimbra, Coimbra, Portugal; ${ }^{2}$ Mary Seacole Centre for Nursing Practice, Thames Valley University, London, United Kingdom; ${ }^{3}$ Faculdade de Ciencias Sociais e Humanas da Universidade Nova de Lisboa, Lisboa, Portugal; ${ }^{4}$ Department of Human Genetics, University of Witwatersrand, Johannesburg, South Africa; ${ }^{5}$ Department of Clinical Genetics, University Hospital, Lund, Sweden; ${ }^{6}$ Faculdade de Medicina de Coimbra, Coimbra, Portugal; ${ }^{7}$ Servico de Genetica, Hospital de Santa Maria, Lisboa, Portugal; ${ }^{8}$ Instituto de Biologia Molecular e Celular, Universidade do Porto, Porto, Portugal; ${ }^{9}$ Medical School, Foresterhill, Aberdeen, Scotland, United Kingdom; ${ }^{10}$ Shriver Center for Mental Retardation, United States; ${ }^{11}$ Instituto de Higiene e Medicina Tropical, Lisboa, Portugal.

Jorge M. Saraiva, Servico de Genetica Medica, Hospital Pediatrico Coimbra, Av. Bissaya Barreto, 3000-075 Coimbra, Portugal; E-mail: hpcgen@hotmail.com.

Received: September 7, 2000

Accepted: February 1, 2001.
}

under debate, and discussion on these topics by scientific societies and patient organizations as well as the general public. Cooperation with media dedicated to accurate reporting will facilitate this. We must improve public knowledge and discussion in order to avoid blind prohibition and to promote ethically guided progress.

In the wake of scientific and cultural globalization, bioethics will gradually become universal. Bioethics will look not only at human dignity, individually and in its societal dimension, but also at protection of the environment and at means of directing scientific and technological development toward the maximum benefit of all humankind.

While exploring ways to derive maximum value from biotechnology without paying a high ethical and social price, we should not forget that what people find acceptable and how they view bioethics can change quickly.

\section{Genetic testing and human rights}

Genetic tests, as defined in the final report of the Task Force on Genetic Testing, USA, 1998, include the analysis of human DNA, RNA, chromosomes, proteins, and certain metabolites in order to detect inherited disease-related genotypes, mutations, phenotypes, or karyotypes for clinical purposes. Such purposes include predicting risk of disease, identifying carriers, and establishing prenatal and clinical diagnosis or prognosis. Prenatal newborn and carrier screening, as well as testing in high-risk families, is included. Tests for metabolites are included only when they are undertaken because there exists a high probability that an excess or deficiency of the metabolite indicates the presence of inherited mutations in single genes. Tests conducted purely for research are excluded, as are tests for somatic (as opposed to inherited) mutations and testing for forensic purposes.

Respect for the classical ethical principles of autonomy, nonmaleficence, fidelity, beneficence, and justice in the process of genetic testing is needed to guarantee an individual's fundamental human rights. We would define these as freedom of choice; the right to full, accurate information; the right to privacy; the right to good, efficient care; and the right to nondiscrimination within a multicultural and multiethnic perspective.

Genetic testing requires appropriate informed consent after nondirective pretest counseling. Support should be provided after a test result is produced. Ideally, genetic tests should be delivered with the support of clinical genetics centers with multidisciplinary teams. This support should be mandatory for presymptomatic testing for disorders with no available 
treatment. Commercial companies offering over-the-counter testing should be compelled to ensure that they comply with the need to provide pre- and posttest genetic counseling.

Genetic testing of children should not be permitted earlier than the usual age of onset of disease or availability of useful treatment. It should not be permitted for adult-onset diseases before the age of maturity. Children to be adopted and their prospective adoptive parents should not be subject to any genetic testing that biological children and parents would not undergo.

Patients and families should be involved in the health care process. There should be ongoing assessment of the quality of genetic counseling as well as of laboratory services in both the public and private sectors.

Guidelines should be created that encourage nondiscrimination in education, employment, health care, and insurance after genetic testing. There is also a need for close vigilance of possible abuse or misuse of genetic information.

\section{Education and communication in human genetics issues}

The scientific findings that generate a strong emotional reaction are those that touch ancestral myths. And only after overcoming the emotional turbulence of fascination or terror and reaching, insofar as possible, a cold objectivity can we have a correct understanding of the scientific, social, and political effects of genetics.

To adopt too much legislation too soon because of public fears may be too restrictive and may make it difficult to evaluate the risks and benefits of the new technology.

To be able to promote accurate public discussion through good, impartial advice, we must know how people make choices and whom they believe. Fear of the unknown is the greatest barrier we have to face. There is an urgent need for further research in this area.

Medical, social, and ethical aspects of genetics should be introduced as a topic in schools, at the undergraduate level in law and medicine, and within other biology, nursing, and allied medicine courses.

There is a need for the development of more accessible and accurate genetics information both in the published literature and on Internet sites for the general public. The media will also have an important role in raising the awareness and understanding of genetics issues.

At the level of research planning, the opinions of individuals, families, and communities to be studied should be sought at an early stage. Full information should be provided about the study, both at individual and community levels, before research begins.

\section{National bioethics committees and the challenge of human genome research}

There is a need for a greater international collaboration among ethics committees. National ethics committees should be independent and should include lay people and social scientists, reflecting in their composition the plurality and diversity of beliefs and religious and cultural values found in each country. Medical and other human geneticists must also be involved in the national ethics committees' work when genetics issues are discussed. Local ethical committees should oversee medical research and practice at the institutional level.

Genetic services should aim to satisfy public needs but not necessarily public wants. All populations should have access to the benefits of human genome research, and there should be equity in resource allocation. In particular, families with rare disorders must be taken into account.

International and social inequalities in health, genetic services, and research should be addressed; discrimination should be prevented; and equity of access for all populations and particularly minority ethnic groups within countries should be promoted. The human genome belongs to all humankind, and the new era of research arising from the completion of the Human Genome Project is the time to commit ourselves further to assisting the developing countries in solving their health problems.

\section{Acknowledgments}

The Portuguese Society of Human Genetics is grateful to the British Council, Fundacao Calouste Gulbenkian, Fundacao para a Ciencia e a Tecnologia, and Fundacao Luso-Americana para o Desenvolvimento for the support that made possible the realization of the meeting "Issues in Human GenEthics." 